\title{
TEACHING METHODOLOGIES FOR IMPROVING DENTAL STUDENTS' IMPLEMENTATION OF ERGONOMIC OPERATOR AND PATIENT POSITIONING
}

\author{
Andrea M. Faust
}

A thesis submitted to the faculty of the University of North Carolina at Chapel Hill in partial fulfillment of the requirements for the degree of Master of Science in Dental Hygiene Education in the Division of Comprehensive Oral Health, Adams School of Dentistry.

Chapel Hill

2020

Approved by:

Jennifer B. Harmon

Sumitha N. Ahmed

Lisa B. Johnston 
(C) 2020

Andrea M. Faust

ALL RIGHTS RESERVED 


\begin{abstract}
Andrea M. Faust: Teaching Methodologies for Improving Dental Students' Implementation of Ergonomic Operator and Patient Positioning

(Under the direction of Jennifer B. Harmon)
\end{abstract}

The aim of this study was to determine the impact of inter-professional teaching on the application of ergonomic operator and patient positioning. A randomized case-control study was conducted with 83 first-year dental students at the UNC Chapel Hill Adams School of Dentistry. Forty-nine percent $(\mathrm{n}=41)$ of the students solicited participated.

All students participated in a didactic lecture on ergonomics, along with a pre-clinical practice session with peer patients. During the clinical practice session students in the case group received ten minutes of one-on-one individualized instruction. Two weeks later, all students were assessed using a rubric on operator and patient positioning, while simulating restorative work.

There was a statistically significant difference between the two groups with respect to the composite ergonomic compliance score $(\mathrm{p}=0.005)$, operator shoulder abduction position $(\mathrm{p}=0.03)$, and lateral flexion of the spinal column $(\mathrm{p}=0.02)$. Hands-on individualized instruction positively effects ergonomic compliance. 


\section{ACKNOWLEDGEMENTS}

I would like to thank: Jennifer Harmon for providing access to the curriculum of the first-year dental students and contributing so much effort towards the calibration and evaluation processes. I would like to thank Sumitha Ahmed for helping us develop a manageable ordinal evaluation system for the rubric. I would especially like to thank Lisa Johnston for encouraging our team to pursue quantitative research. Lisa further requested that the rubric be presented in a picture format for the evaluation process. Thank you all for contributing so much to this project. Finally, Ceib Phillips was integral in helping us understand the numbers. Thank you for all your patience, Ceib.

A special thanks to Bethany Valachi, who allowed me to interview her prior to developing this study. Bethany expressed that positioning for the correct arch can be one of the major points of disconnect for novice students. Some of this research design was developed around this observation. I would also like to thank Brian Partido for communicating with me via email about much of the exciting research he has conducted. A special thank you to Jehan

\section{Alalkami, Roxanne Dsouza, Caroline McLeod, Judith Beck, Rachel Labella, and Julia}

Zhang for volunteering to contribute to this project. This is dedicated to my parents. You taught me to strive for knowledge and pursue excellence in everything. I also have to thank my husband for so much love and support during this process. 


\section{TABLE OF CONTENTS}

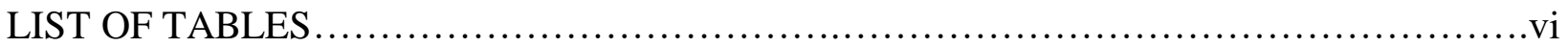

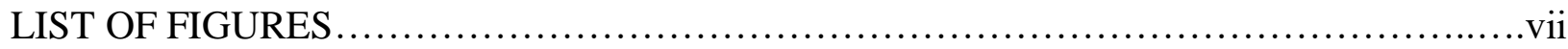

LIST OF ABBREVIATIONS ...........................................................



II. REVIEW OF THE LITERATURE............................................4

Ergonomic Training among Healthcare Professionals.........................4

Multifactorial Ergonomic Training among Practicing Dental Professionals.......6

Studies on Dental Students Knowledge of Ergonomics.........................7

Studies on Dental Students Managing Pain through Exercise...................9

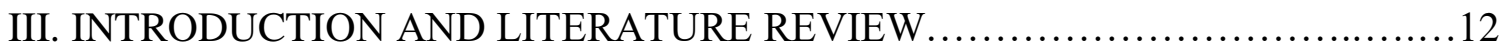

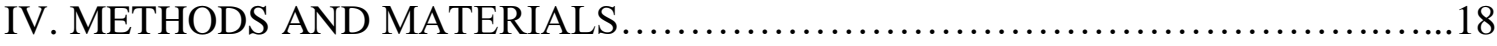

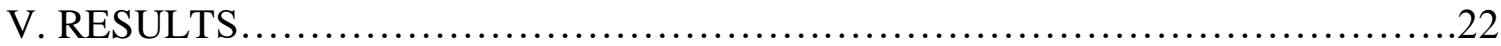

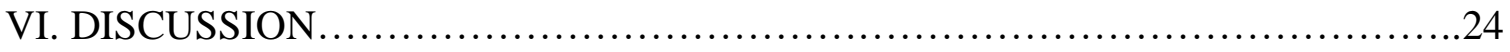



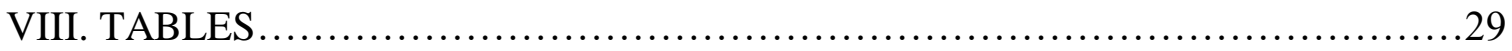

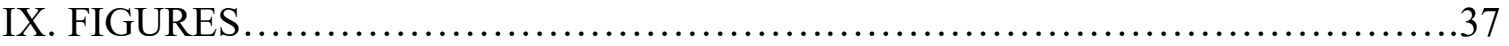

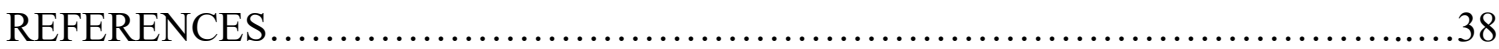




\section{LIST OF TABLES}

Table 1.1 Rubric for Ergonomic Compliance Evaluation....................................29

Table 1.2 Picture Rubric Utilized for Evaluation...................................... 30

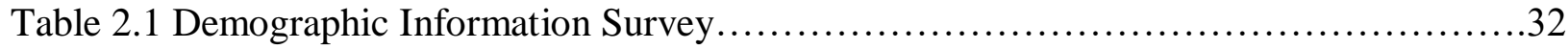

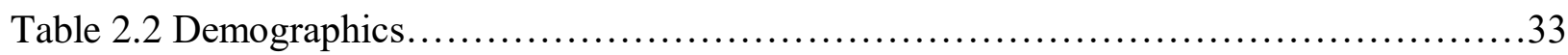

Table 3.1 Mantel-Haenszel Row Mean Score for the Case and Control Groups.................34

Table 3.2 Bivariate Unpaired T-test for Composite Scores ................................34

Table 4 Multivariate GLM Performed to the Bivariate Analysis.............................35

Table 5 Mean Scores of Ergonomic Compliance of the Case and Control Groups..............36 


\section{LIST OF FIGURES}

Figure 1 Box Plot for Composite Scores of Ergonomic Compliance...........................37 


\section{LIST OF ABBREVIATIONS}

MSD Musculoskeletal Disorder

PE Participatory Ergonomic 


\section{INTRODUCTION}

Musculoskeletal disorders (MSDs) have been shown to have a high prevalence among careers that require prolonged static posturing. Dentistry is high on the list of professions necessitating intense, precision based, psychomotor skills. ${ }^{1-4}$ Dentistry is also predominantly preformed in a seated position. Prolonged sitting has been linked to cervical and lumbar intervertebral disc deterioration, caused by increased pressure. ${ }^{5}$ Poor posturing and repetitive movements are also critical factors to consider; certainly, the cause of these MSDs is multifactorial. ${ }^{6}$ A systematSic review of the literature on dental professionals developing MSDs, produced by Hayes et al., shows that the prevalence of MSDs among dental professionals is between $64 \%$ and $93 \%,{ }^{2}$ well over half of working clinicians. Hayes acknowledges that research on the topic is limited and somewhat contradictory. The author notes that participants of surveys may be biased, as those who experience MSDs may be more willing to participate in surveys and data collection. Regardless of how qualitative the methodology of current studies are; the fact remains, study after study has shown that dental care providers are at a high risk for developing occupational cumulative trauma. $1,3,4,6-9$

The variety of MSDs impacting dental health professionals is diverse and often linked directly to the nature of the occupational tasks completed. Dental hygienists and dental assistants report greater frequency of upper back, neck, and shoulder pain. ${ }^{2,3,8}$ Dental hygienists specifically experience the highest prevalence of arm, wrist, and hand pain. ${ }^{2}$ Valachi explains this may correlate to the fact that performing prophylaxis and maintenance scaling is a highly 
repetitious fine-motor task. ${ }^{6}$ Dentists also experience these MSDs but they have the distinction of having the greatest frequency of low back pain. ${ }^{2,6,10}$

One of the reasons dentists experience a higher prevalence of low back pain may be the nature of the static postures they maintain while working in a specific area of the mouth. These static postures may simply place more strain on the lumbar region. Valachi explains that in order to hold static postures, the body uses well over $50 \%$ of its muscles to the hold the body motionless against the forces of gravity. ${ }^{6}$ The advent of four handed dentistry increased the efficiency of dental work production, but inflicted a steep toll on the clinician's body. Another consideration is the vast majority of dental hygienists and dental assistants are women. Dentistry was once a male dominated field, but over time has become a gender-neutral profession. Taller male clinicians may account for some of the increase in low back pain. Men do not necessarily develop a higher incidence of $\operatorname{MDSs}^{11}$; rather, environmental equipment is often tailored to average height individuals. This places taller clinicians at a disadvantage. In some cases the highest setting of a clinician's chair may be too low, obstructing a neutral pelvic position. ${ }^{12}$ Some studies show female dentists have even greater amounts of low back pain than their male counterparts. ${ }^{13}$ The reason for gender differences is not clear.

Recognizing the diverse nature of MSDs, clinician tailored education in ergonomics is the key to prevention of these conditions. Ergonomics is the applied science of studying the work environment, in order to make environmental changes and physical modifications that will promote safety and efficiency for employees. Practicing ergonomics greatly reduces the risk of injuries and developing MSDs. ${ }^{12}$ Continuing education for the working professional is an excellent opportunity to address the concerns of actively working dentists. However, the best treatment of MSDs is prevention of MSDs. Therefore, students of dentistry must be given a 
strong foundation in ergonomics to address their unique personal considerations. Indeed, Samoladas et al. surveyed Greek dental students in their fourth and fifth years of dental school and found almost $50 \%$ already reported pain in their back. ${ }^{7}$ The pain pattern correlated with the start of clinical care. Consequently, students need knowledge about ergonomics from the inception of their education. It is harder to correct bad habits than it is to develop good habits from the beginning. Graduates also need this knowledge before they invest in expensive equipment and develop a routine work schedule for themselves and their staff. Dental educators have a duty to advocate for the health and wellbeing of future practitioners. 


\section{REVIEW OF THE LITERATURE}

\section{Ergonomic Training among Healthcare Professionals}

In a systematic review of participatory ergonomic (PE) programs, Rivilis et al. showed that the majority of studies on implementation of a PE program produced a reduction in MSD pain. ${ }^{14}$ PE programs involve teams of workers being trained in ergonomics and disseminating information to their bosses and colleagues. This practice results in workers developing and implementing ergonomic changes in their work environment. While, the practices of working environments are different from student instructional settings, workers are adult learners. Therefore, the results of this study may be applied to the educational setting. What is notable about PE programs is that they require active participation of the workers. The success or failure of these programs stems from the involvement of employees and employer compliance. The workforce must be willing to practice modifications and the employer must be willing to make environmental changes such as scheduled breaks or equipment changes.

The systematic review argued that of the 12 studies that met the rigorous criterion for evaluation, the majority of the cases did not adapt sound methodological approaches to measuring the impact of PE programs. Only 1 of the 12 included studies met the criterion to be considered of a high-quality methodological strength. The results of that particular study did not find a correlation between PE and reduction of MSD related pain. ${ }^{14}$ Rivilis argues that more rigorous and methodologically sound research is required to move the field of ergonomics forward. 
Baumann et al. expanded on this work by appraising the value of the Canadian PE program EPIC (Ergonomic Program Implementation Continuum). ${ }^{15}$ The authors evaluated six pilot sites in Ontario Canada, to determine how effective the PE training and coaching of the participants was, in regards to promoting a culture of safety. The employees had a positive response to the program and they reported that dedication of organizational leaders and coaches was pivotal to the continued success of the program. Bauman also emphasizes the teachings of J. R. Wilson a pioneer of PE. Participatory ergonomics acknowledges that ergonomics is an active discipline, requiring practitioners of it to routinely evaluate themselves and their working environment. Suggesting that ergonomics as a field should not be learned in isolation through didactic instruction alone. Rather, mastery of ergonomic interventions requires critical thinking, working knowledge of anatomy and biomechanics, and awareness of what ergonomic equipment exists and how to adjust it correctly. ${ }^{15}$

Szeto et al. completed a multifaceted ergonomic intervention program with a community of nurses, from four different Hong Kong hospital settings. ${ }^{16}$ The program interventions included 8 weeks of training in: ergonomics, equipment modification, daily exercise, work station assessment, and typing. The results showed a significant improvement in MSD related pain, which the nurses were able to maintain at a post-instruction one year follow up assessment. The study is notable because it included the incorporation of a physical exercise program and a physiotherapist. The physiotherapist met and observed all of the participating nurses twice during the program. Photographic images were taken of the participants and they were given an opportunity to evaluate themselves and later participated in a group discussion to generate solutions to non-ergonomic working practices. 
This study cannot be generalized to suggest that dental students would have the same response, but several aspects of the research are notable. The nurses who suffered MSDs continued to apply the ergonomic practices because their pain remained greatly reduced up to a year after completing the training. The nurses also had time to work individually and hands-on, with the physiotherapist in their work setting. This is very different from watching a video or receiving a lecture on ergonomics. Much like dental students need operational clinical practice to develop competency in restorative work, they may benefit from consulting with ergonomic specialists while performing patient care. It is difficult to know if the nurses continued to practice the daily physical exercises completed during the program. The follow up survey did not detail this question. Further study into compliance with routine exercises might elucidate how big an impact routine targeted exercises can have on MSD pain management of working healthcare professionals.

\section{Multifactorial Ergonomic Training Studies among Practicing Dental Professionals}

A systematic review of the literature was conducted on ergonomic interventions reducing MSDs among dental practitioners by Mulimani et al. ${ }^{17}$ Three authors independently screened and selected 20 articles from over 946 references related to the topic. An independent panel created selection criterion for inclusion analysis. Only two articles of the twenty were of a high enough caliber to be included in the systematic analysis. The articles failed to show a risk reduction in MSDs through ergonomic interventions. One might assume that ergonomics do not prevent MSDs based on this systematic analysis; however, the analysis showcases that the quality of research in the field is limited and of low methodological standards. Therefore, ergonomics is a burgeoning field ready to be explored. 


\section{Studies on Dental Student Knowledge of Ergonomics}

In 2011, Garbin et al. conducted research among Brazilian dental students assessing their knowledge of ergonomics in their senior year of dental school and their application of these ergonomic practices. ${ }^{18}$ The authors took photographs of the students as they worked in clinical care. Later the students evaluated the photographs for postural accuracy. They had a nonergonomically trained researcher take the photographs of the dental students in 8 specific positions to reduce the bias of the photographs. Perhaps a more accurate assessment of the general postural positions could have been obtained from filming the students. In the study $65 \%$ of the assessments regarding ergonomic or non-ergonomic positions were evaluated correctly by the students. Only $35 \%$ of photographs met ergonomic standards. Further analysis of the images noted that incorrect lighting positioning was a key contributing factor to non-ergonomic headforward or torso tilted positioning. This is a common misalignment made by dental practitioners. The authors suggested further study into the curriculum of ergonomics as students were not positioning or recognizing ergonomic positioning to an acceptable standard.

Partido et al., of the United States, had a similar amount of success training dental hygiene students in assessment of proper ergonomic posture through capturing photographs. ${ }^{19}$ All students involved in the study received didactic training in ergonomic posture in their preclinic setting reinforced with a photography self-evaluation session lead through three clinical raters. The intervention group received further photography based self-assessment opportunities over a period of two weeks, receiving extra feedback from the three calibrated clinical raters. Finally, all participants had a final photography based self-evaluation opportunity. The research showed more attuned assessments between the clinical raters and the students who participated in the intervention group. The overall response from the students also suggested that the self- 
assessment opportunity made them more aware of their positioning. Partido recognizes that theoretical knowledge and practical application are not the same thing. If instructors want students to apply ergonomics then students need to be assessed on its application in the clinical setting. Much like other psychomotor skills students are trained in, the more it is practiced, the greater the improvement in application.

Garcia et al. evaluated the experiences of Brazilian dental students practicing ergonomics in their senior year, through an interview process. ${ }^{20}$ The interview revealed that $59 \%$ of students recognized the value of proper ergonomic positioning. Furthermore, $62 \%$ of students admitted to experiencing difficulty when attempting to achieve proper ergonomic posture. Presoto et al. built further upon Garcia's ${ }^{20}$ work at the same university assessing dental students' knowledge of work related risk factors for developing MSDs. ${ }^{21}$ The author recognized the importance of awareness of risk factors in influencing the individual to preemptively practice ergonomics. The author explains that, "such assessments may provide insight into the adequacy of the training process to protect dentists' occupational health." ${ }^{21}$ Presoto found that women had a higher academic level of awareness of risk factors and suggested this may be due to a higher incidence of pain among women. The author referred to a study completed by Hofftman et al. which suggested that women may have a lower threshold for pain due to biological differences in their skeletal masculinization. ${ }^{22}$ Other literature has also shown that women are at a higher risk for developing MSDs. ${ }^{8,23}$ Presoto determined that the students surveyed generally had a moderate to high understanding of ergonomics due to their course curriculum. Yet, the standards for teaching ergonomics are far from universal.

Research completed by Cervera-Espert et al. in Spain produced different results. ${ }^{24}$ There were no significant differences in perception of ergonomic awareness between male and female 
students. When clinically evaluated for proper ergonomic posture only $29 \%$ of students were able to sit correctly in their operator chair. Students also reported inadequate instructional content in ergonomics and operator positioning throughout their curriculum. Similar to previous survey based studies the population felt confident they understood ergonomics. However, the only way to accurately obtain how knowledgeable students are in ergonomics would be to assess their knowledge directly. It was notable that while the students reported moderate to high knowledge of ergonomic principles, a notable amount of students were unable to identify what the concept of BHOP (balanced human operator position) meant. This was an explicitly taught mnemonic for correct operator positioning. Students had previously received training in the BHOP model during both their first and second years of dental school. The author also noted a loss of confidence in knowledge of ergonomics the farther the students progressed into their academic career. The author concedes that dental students simply need more tailored training in ergonomics. Inter-professional learning opportunities should be developed with ergonomic professionals and integrated into existing curriculum content. Students should also be routinely encouraged to evaluate and apply ergonomics in clinical settings to retain understanding.

\section{Studies on Dental Students Managing Pain through Exercise}

A Croatian sought to study the overall effect of exercise on prevention of low back pain among dental students. ${ }^{13}$ Dental students at the University of Zagreb have the option of enrolling in a physical fitness course during their regular academic course load. All students who participated in the study were surveyed regarding their routine physical exercise practices. In order to avoid biases from the potential inflation of the students' perceptions of their cardiovascular stamina, the authors also encouraged students to participate in an astrand ergometer bicycle test. However, this endurance exercise data was separated from the final data 
analysis of students who participated in the evaluation. Therefore, the general results are correlative of the students' opinions of their physical fitness and self-reported exercise habits.

In summation those students who participated in the physical fitness course throughout the year had significantly less low back pain than those who did not. While some students reported exercising 2 or 3 times weekly, the accountability of a routine class may have enabled those students to maintain a higher physical stamina. The astrand ergometer bicycle test further supported this theory. Among those who failed the test the majority were not exercising at all. A moderate correlation was noted between those who were enrolled in the physical fitness course and those who performed well on the endurance evaluation. This research further suggests that exercise can play a key role in prevention of MSDs, but it also emphasizes the stipulation that such exercise must be done consistently to yield results.

In 2012 a randomized controlled study, completed by Shankarapillai et al. in Udaipur India, showed that yoga practice could have a significant impact on stress reduction for dental students completing their first periodontal surgery. ${ }^{25}$ The group that received the intervention participated in a 60 minutes session on guided breathing, meditative relaxation, joint exercises, and yoga postures. The control group received a lecture on how stress, relaxation, and health can impact the body. While it is true that this research did not assess pain or MSDs, a relationship between anxiety, stress, and MSDs exists. ${ }^{26}$ This study shows that actively practicing and participating in stress reduction exercises can reduce anxiety. When anxiety is low the individual remains in a calm state; however, when individuals become stressed their sympathetic nervous system is activated, leading to increased muscle tension throughout the body. ${ }^{26}$ Tension that can negatively lead to the development of trigger points, muscle ischemia, and myofascial pain. ${ }^{6}$ The author emphasizes that the intervention generally took place 10 days before the surgical 
procedures. This is important for efficacy because a single yoga session cannot perpetually reduce anxiety. Rather, routine care is necessary to maintain improved health. This study illustrates that students cannot simply be given information in the theory of exercises. Instead they must be required to physically try these activities and continually encouraged to practice such exercises.

Monson et al. led a bi-weekly hour long yoga session amongst dental hygiene students. ${ }^{27}$ A control group was also surveyed regarding MSDs during the research. A reduction in active pain sites with the exception of the shoulder and arm was noted in the yoga treatment group. Current pain sites in the non-participating group remained generally unchanged suggesting that routine exercise can reduce pain, particularly in the low back. Yoga exercise is unique in that it involves the incorporation of deep diaphragm breathing throughout the practice. Such breathing techniques have been shown to stimulate the vagal nerve, activating the parasympathetic nervous system. ${ }^{26}$ As previously stated the parasympathetic nervous system activation can have a notable impact on reduction of muscle tension. The practice of yoga also increases body awareness, which may improve posture by promoting clinicians to be more aware of their muscle engagement and positioning. When designing a manageable exercise routine for dental health clinicians we must consider how versatile specific exercises may be. Yoga has the potential for strengthening of key core and shoulder girdle muscle groups along with stress reduction effects. 


\section{INTRODUCTION AND LITERATURE REVIEW}

Musculoskeletal disorders (MSD) have been shown to have a high prevalence among careers that require prolonged static posturing. Dentistry is high on the list of professions necessitating intense, precision based, psychomotor skills. ${ }^{1-4}$ Dentistry is also predominantly preformed in a seated position. Prolonged sitting has been linked to cervical and lumbar intervertebral disc deterioration, caused by increased pressure. ${ }^{5}$ Poor posturing and repetitive movements are also critical factors to consider; certainly, the cause of these MSDs is multifactorial. ${ }^{6}$ A systematic review of the literature on dental professionals developing MSDs, produced by Hayes et al., shows that the prevalence of MSDs among dental professionals is between $64 \%$ and $93 \%,{ }^{2}$ well over half of working clinicians. Hayes acknowledges that research on the topic is limited and somewhat contradictory. The author notes that participants of surveys may be biased, as those who experience MSDs may be more willing to participate in surveys and data collection. Regardless of how qualitative the methodology of current studies are; the fact remains, study after study has shown that dental care providers are at a high risk for developing occupational cumulative trauma. ${ }^{1,3,4,6-9}$

The variety of MSDs impacting dental health professionals is diverse and often linked directly to the nature of the occupational tasks completed. Dental hygienists and dental assistants report greater frequency of upper back, neck, and shoulder pain., ${ }^{2,3,8}$ Dental hygienists specifically experience the highest prevalence of arm, wrist, and hand pain. ${ }^{2}$ Valachi explains this may correlate to the fact that performing prophylaxis and maintenance scaling is a highly 
repetitious fine-motor task. ${ }^{6}$ Dentists also experience these MSDs but they have the distinction of having the greatest frequency of low back pain. ${ }^{2,6,10}$

One of the reasons dentists experience a higher prevalence of low back pain may be the nature of the static postures they maintain while working in a specific area of the mouth. These static postures may simply place more strain on the lumbar region. Valachi explains that in order to hold static postures, the body uses well over $50 \%$ of its muscles to the hold the body motionless against the forces of gravity. ${ }^{6}$ The advent of four handed dentistry increased the efficiency of dental work production, but inflicted a steep toll on the clinician's body. Another consideration is the vast majority of dental hygienists and dental assistants are women. Dentistry was once a male dominated field, but over time has become a gender-neutral profession. Taller male clinicians may account for some of the increase in low back pain. Men do not necessarily develop a higher incidence of $\mathrm{MDSs}^{11}$; rather, environmental equipment is often tailored to average height individuals. This places taller clinicians at a disadvantage. In some cases the highest setting of a clinician's chair may be too low, obstructing a neutral pelvic position. ${ }^{12}$ Some studies show female dentists have even greater amounts of low back pain than their male counterparts. ${ }^{13}$ The reason for gender differences is not clear.

Recognizing the diverse nature of MSDs, clinician tailored education in proper ergonomic positioning is the key to prevention of these conditions. Ergonomics is the applied science of studying the work environment, in order to make environmental changes and physical modifications that will promote safety and efficiency for employees. Practicing proper ergonomic positioning greatly reduces the risk of injuries and developing MSDs. ${ }^{12}$ Continuing education for the working professional is an excellent opportunity to address the concerns of actively working dentists. However, the best treatment of MSDs is prevention of MSDs. 
Therefore, students of dentistry must be given a strong foundation in safe effective body postures to address their unique personal considerations. Indeed, Samoladas et al. surveyed Greek dental students in their fourth and fifth years of dental school and found almost $50 \%$ already reported pain in their back. ${ }^{7}$ The pain pattern correlated with the start of clinical care. Consequently, students need knowledge about ergonomics from the inception of their education. It is harder to correct bad habits than it is to develop good habits from the beginning. Graduates also need this knowledge before they invest in expensive equipment and develop a routine work schedule for themselves and their staff. Dental educators have a duty to advocate for the health and wellbeing of future practitioners.

\section{Ergonomic Training Among Healthcare Professions}

In a systematic review of participatory ergonomic (PE) programs, Rivilis et al. showed that the majority of studies on implementation of a PE program produced a reduction in MSD pain. ${ }^{14}$ While, these working environments are different from student instructional settings, workers are adult learners. Therefore, the results of this study can be applied to the educational setting. Szeto et al. completed a multifaceted ergonomic intervention program with a community of nurses, from four different hospital settings in China. ${ }^{16}$ The results showed a significant improvement in MSD related pain, which the nurses were able to maintain at a post-instruction one year follow up assessment. The study is notable because it incorporated a physiotherapist, who met with and observed all of the participating nurses twice during the program. The nurses worked both hands-on and individually with the physiotherapist in their regular work environment. 


\section{Multifactorial Ergonomic Training Studies among Practicing Dental Professionals}

A systematic review of the literature was conducted on ergonomic interventions reducing

MSDs among dental practitioners by Mulimani et al. ${ }^{17}$ Three authors independently screened and selected 20 articles from over 946 references related to the topic. An independent panel created selection criterion for inclusion analysis. Only two articles of the twenty were of a high enough caliber to be included in the systematic analysis. The articles failed to show a risk reduction in MSDs through ergonomic interventions. One might assume that ergonomics do not prevent MSDs based on this systematic analysis; however, the analysis showcases that the quality of research in the field is limited and of low methodological standards. Therefore, ergonomics is a burgeoning field ready to be explored.

\section{Studies on Dental Student Knowledge of Ergonomics}

In 2011, Garbin et al. conducted research among Brazilian dental students assessing their knowledge of ergonomics in their senior year of dental school and their application of these ergonomic practices. ${ }^{18}$ The authors took photographs of the students as they worked in clinical care. Later the students evaluated the photographs for postural accuracy. They had a nonergonomically trained researcher take the photographs of the dental students in 8 specific positions to reduce the bias of the photographs. In the study $65 \%$ of the assessments regarding ergonomic or non-ergonomic positions were evaluated correctly by the students. However, only $35 \%$ of the student photographs met ergonomic standards. The authors recommended further study into the curriculum of ergonomics, because students were neither positioning nor recognizing ergonomic positioning to an acceptable standard. 
Partido et al., of the United States, had a similar amount of success training dental hygiene students in self-assessment of proper ergonomic posture through photographs. ${ }^{19}$ Students involved in the study received didactic training in ergonomic posture in their pre-clinic setting reinforced with a photography self-evaluation session, lead through three clinical raters. The intervention group received further photography based self-assessment opportunities over a period of two weeks, receiving extra feedback from the three calibrated clinical raters. The research showed more attuned assessments between the clinical raters and the students who participated in the intervention group. The overall response from the students also suggested that the self-assessment opportunity made them more aware of their positioning.

Garcia et al. evaluated the experiences of Brazilian dental students practicing ergonomics in their senior year, through an interview process. ${ }^{20}$ The interview revealed that $59 \%$ of students recognized the value of proper ergonomic positioning. Furthermore, $62 \%$ of students admitted to experiencing difficulty when attempting to achieve ergonomic posture. Presoto et al. built further upon Garcia's ${ }^{20}$ work at the same university assessing dental students' knowledge of work related risk factors for developing MSDs. ${ }^{21}$ The author recognized the importance of awareness of risk factors in influencing the individual to preemptively practice ergonomics. The author explains that, "such assessments may provide insight into the adequacy of the training process to protect dentists' occupational health." ${ }^{21}$ Presoto determined that the students surveyed generally had a moderate to high understanding of ergonomics due to their course curriculum.

Research was completed by Cervera-Espert et al. in Spain, which interviewed students at various undergraduate and postgraduate levels. Both knowledge of ergonomics and student's ability to sit correctly in an operator chair were evaluated. ${ }^{24}$ Only $29 \%$ of students were able to sit correctly in their operator chair. Students also reported inadequate instructional content in 
ergonomics and operator positioning throughout their curriculum. Similar to previous survey based studies the population felt confident they understood ergonomics. Yet while students reported moderate to high knowledge of ergonomic principles, a notable number of students were unable to identify what the concept of BHOP (balanced human operator position) meant. This was an explicitly taught mnemonic for correct operator positioning. Students had previously received training in the BHOP model during both their first and second years of dental school. The author also noted a loss of confidence in knowledge of ergonomics the farther the students progressed into their academic career. The author concedes that dental students simply need more tailored training in ergonomics.

The research shows that both the development of MSDs and the prevention-treatment of MSDs is multifactorial. ${ }^{6,12}$ Dental students should learn about anatomy/physiology, kinesiology, and biomechanics of the body in order to understand how MSDs develop. From this understanding students can then begin to combat the forces of stress placed on their body through knowledge of dental equipment, along with correct operator and patient positioning. Postural awareness is a critical component to this process. ${ }^{6}$ The work of Partido ${ }^{19}$ and Garbin ${ }^{18}$ showed that self-assessment through photography is a great way of motivating students to develop awareness of their own postural positioning.

While it remains true that ergonomics is an applied science, this research will focus on knowledge acquisition of ergonomic practices for novice learners, first-year dental students, mastering correct operator and patient positioning. As such, this research will borrow from PE program models, by implementing an opportunity for tailored hands-on instruction in equipment usage, operator positioning, and patient positioning. 


\section{METHODS AND MATERIALS}

A convenience sample of 83 first-year dental students at the University of North Carolina at Chapel Hill, Adams School of Dentistry, served as subjects for a case control study on teaching methodologies for proper ergonomic posture. All students participated in a two-hour didactic lecture on proper ergonomic postures and positioning. The lecture objectives included: discussion on why ergonomics is important for dental clinicians, analysis of what MSDs are prevalent among dental clinicians, and application of correct operator and patient positioning. Students present during the lecture were invited to participate in the study through consent forms. Among the students present, 73 students agreed to participate in the research.

The IRB \#19-0243 project received exemption status from the University of North Carolina at Chapel Hill Institutional Review Board. The subjects did not encounter harm but received additional pedagogical instruction. All students who agreed to participate were eligible to withdraw from the research at any point. Initially, some participants may have felt uncomfortable when assuming recommended postures; however, all postures that were

recommended were known to reduce injury and decrease muscle fatigue. ${ }^{28}$ The control group students were also offered the opportunity to engage in the hands-on instruction, after the evaluations were complete.

The null hypothesis stated that there would be no difference in the mean scores for proper ergonomic posture compliance between the case group of students who received hands-on individualized instruction and the control group of students who did not. The case and control 
groups were assigned through a block randomization design. The research committee discussed the possibility of stratifying the case and control groups by age, ethnicity, and gender; however, due to the small sample size and the possibility of participant withdraw, random assignment was utilized.

Of those who agreed to participate in the research, 36 students were placed in a control group and received no additional instruction. The other 37 students served as the case group. The case group met in the clinical setting for additional one-on-one instruction with facilitators that included two physical therapy students, a physical therapy faculty member, and three dental hygiene instructors, all of whom were trained in effective ergonomic postures and positioning. These students were shown live demonstrations of correct operator and patient positioning. Afterward, they practiced correct operator and patient positioning through peer patient practice. Tailored feedback was provided by the facilitators.

Two weeks after the peer patient pre-clinical instruction, control and case group students, were assessed by two faculty members on operator and patient positioning through a simulated patient experience. The faculty evaluating the participants were calibrated prior to assessment for inter-examiner reliability. This calibration was achieved by having the evaluators separately assess existing photographs of dental positioning with the developed rubric. The scores were cross-compared until the evaluators consistently evaluated images with nearly equivalent scores, allowing for no more than one degree of difference in only one of the eight outcome variables evaluated.

The rubric was developed through consultation with existing literature on correct operator and patient positioning. ${ }^{6,28,29}$ An ordinal scale from ideal, to acceptable, to unacceptable was developed for each outcome variable of ergonomic posture assessed. Eight 
outcome variables were assessed which included: hip flexion, lumbar placement, shoulder abduction, neck flexion, thoracic posture (in relation to forward head posture), lateral flexion of the spinal column, elbow flexion (corresponds with height of the patient chair), and the angle of the patient's maxillary or mandibular arch. Discussion on including operator clock position occurred, but since ergonomic positions can be achieved at more than one clock position this was not included. Light positioning was also excluded from this research because many dental clinicians are now utilizing headlight apparatuses.

Each outcome variable needed its own unique range of values for the ordinal categorization of ideal, acceptable, and unacceptable. Standards were developed for each range (Table 1). In order to facilitate the classification of the values of ideal, acceptable, and nonacceptable during the student evaluation process a picture rubric of these postures was utilized. The images were selected to accurately display the range of measurements expressed for each outcome variable. Clarification discussion for ideal, acceptable, and unacceptable was further developed during the calibration process. For instance, the evaluators decided that any student not contacting the lumbar support would receive a score of unacceptable, regardless of the lumbar height.

The assessment process involved participants placing themselves into working positions for three different working areas of the mouth: a mandibular posterior tooth, an anterior tooth, and finally a maxillary posterior tooth. The sites were selected to assess for correct working postures in all areas of the mouth. The third working area positioned was photographed for post analysis assessment of score calibration. A mean for the three scores of the different working areas was obtained. The mean scores for the eight areas assessed were calculated into a composite score, where each outcome variable that was measured held equal weight in the 
scoring. Since students received a 0 for any unacceptable scores, a 1 for any acceptable scores, and a 2 for any ideal scores their composite score fell inside a range of 0 to 2 for ergonomic compliance.

The data was collected during two separate sessions. Students were observed assuming operator and patient positioning for restorative work on tooth numbers 29, 6, and 15 (Universal tooth numbering system). The operator chair and patient chair were reset to a standard position at the start of each new student evaluation. All students evaluated were right handed clinicians. Left handed clinicians would have been given inverted corresponding teeth; however, no left handed students were evaluated.

After the data was collected a Mantel-Haenszel Row Mean Score was applied to each of the eight ergonomic postures assessed for the case and control groups. The composite score yielded normally distributed results, so an unpaired T-test was performed to assess the effect of the intervention, age, ethnicity, and gender on the composite score.

During the bivariate analysis of the data, ethnicity was shown to be a possible confounding variable $(\mathrm{p}=0.005)$. A multivariate generalized linear model (GLM) was performed to assess whether ethnicity, gender, or age range were statistically significant enough to confound the relationship between the intervention and the composite score. Race was collapsed into the categories of Caucasian and all other ethnicities. Age was also collapsed into 20-24 years old and 25 years or older. The level of significance was set at $\alpha=0.05$ for all data evaluated. 


\section{RESULTS}

During the data collection phase, 28 students withdrew from the research. Data could not be obtained from two students due to time constraints. One student in the case group was excluded from the data analysis because they failed to receive the one-on-one intervention prior to evaluation. Another student was excluded because they were already an RDH and therefore not a novice learner of ergonomic practices. Forty-one students $(n=41)$ were evaluated in the data collection phase. Of the 41 novice, first-year dental students evaluated, 21 students participated in the case group, receiving additional hands-on operator and patient chair positioning instruction and 20 students participated in the control group. Table 2.1 compares the demographics of the case and control groups. The distribution of gender and age between groups was similar ( $p>0.05)$; however, the ethnic representation in the two groups was statistically significantly different ( $\mathrm{p}=0.005)$, with the control group having greater diversity.

Tables 3.1 details the case and control descriptive statistics for the 8 areas of ergonomic compliance assessed: hip flexion, lumbar placement, shoulder abduction, neck flexion, thoracic posture (in relation to forward head posture), lateral flexion of the spinal column, elbow flexion (corresponds with height of the patient chair), and the angle of the patient's maxillary or mandibular arch. Statistically significant differences in the mean values were noted between the case and control groups in the areas of operator shoulder abduction $(\mathrm{p}=0.029)$, and lateral flexion of the spinal column $(\mathrm{p}=0.021)$. The mean composite score was also statistically significantly 
different between the two groups $(\mathrm{p}=0.005)$. Figure 1 displays a box and whisker plot comparison of the composite scores of the case and control groups.

A multivariate analysis with group, gender, age and race as explanatory variables was performed on the composite score (Table 5). Age and gender were not statistically significant ( $>0.05$ ) when controlling for other variables. The comparison between Caucasian students and a collapsed group of all other ethnicities was statistically significant $(\mathrm{p}=0.025)$. When controlling for the demographic variables, the difference in the case and control group mean composite scores $(\mathrm{p}=0.040)$ remained statistically significant. The case group's composite mean score was 0.27 points higher than the control group's mean score; suggesting, a positive correlation between hands-on instruction and compliance with operator and patient positioning. 


\section{DISCUSSION}

Reliability of evaluator scoring for proper ergonomic compliance is critical to ensure that systematic error does not produce invalid results. The evaluation process needs to be detectable through visual observation and have a high inter-rater reliability rate. The Modified-Dental Operator Posture Assessment Instrument (M-DOPAI) with 12 components has been historically used for assessing posture compliance. ${ }^{19}$ Yet, this assessment does not include evaluation of the patient's arch position. Garcia et al. produced a reliable evaluation method. However, the intricacies of the 14 areas of ergonomic compliance and the variability within each of the areas, proved impractical for rapid evaluation. ${ }^{29}$ Therefore a simplified rubric assessing 8 areas of ergonomic compliance was developed through analysis of various scoring rubrics.

In order to ensure observational agreement, a photographic image of students in their final operator posture was captured for post analysis calibration. The images were taken from one vantage point, but they did not always show all aspects of operator and patient posturing, due to the variability of operator positions. The evaluators analyzed the images after the live evaluations were completed. The inter-rater reliability between the live evaluation score and the second evaluator's score for the photographic image was $65.05 \%$, with the evaluators agreeing on 175 out of 269 assessments. However, the inter-rater reliability increased when both evaluators assessed the same photographic images to $86.67 \%$, with evaluators agreeing on 208 out of 240 assessments. 
This discrepancy between intra-rater evaluations of a live assessment compared to a single photographic image, may highlight the need for multiple photographic images from several vantage points when assessing operator and patient positioning. A single photographic image may not capture proper vision of all aspects of ergonomic compliance. For instance, an image showcasing neck and wrist position may obstruct vision of shoulder abduction. Refinement in the validity of ergonomic posture assessment will continue to evolve as assessment of proper ergonomic compliance becomes more prevalent in the dental curriculum.

A single intervention experience was utilized for the purpose of this observational study but historically many similar studies have shown more significant improvements with multiple interventions longitudinally conducted. ${ }^{19}$ The probability values for elbow flexion $(\mathrm{p}=0.066)$ and arch position $(\mathrm{p}=0.067)$ were not quite statistically significant but along with lumbar placement, these three concepts proved to be the most challenging to master. These areas had the lowest mean scores among both the case and control group (Table 5). Some proper ergonomic postures may prove more difficult to master than others. Therefore, further interventions focusing on these areas may help students perform better in these areas.

Cervera-Espert et al. concluded that students had decreasing confidence in their knowledge of ergonomics as they advanced throughout their curriculum. ${ }^{24}$ Suggesting, that students are taught about ergonomic knowledge early in their academic career but receive little, if any feedback on ergonomic compliance as they progress through their programs. The qualitative research of Garcia et al. further highlights the need for reinforcing learned ergonomic concepts in the clinical setting, as $62.1 \%$ of the students interviewed confirmed having difficulties with achieving ergonomically compliant postures. ${ }^{20}$ We would recommend 
reinforcing feedback by having further individualized instruction with dental students throughout their clinical career.

Conversely, some ergonomic postures were intuitively mastered. Hip flexion, which involves the height of the operator, had nearly identical mean scores between the case group and the control group. The use of the A-dec 500 dental chair throughout the Adams School of Dentistry may have contributed to these scores. The default setting for the chair retains a tilted pan seat and the maximum chair height fully accommodates clinicians over 6 feet in height. The ease of adjustment of the chair pan, lumbar, and piston likely contributes to the success or failure of the operator.

This study did have several limitations, the most significant of which was the sample size 41 students. Further investigation is warranted with larger sample sizes. Race proved to be a covariate for ergonomic compliance. Further investigation would be necessary to determine whether the source of this relationship is a physical difference or a cultural influence. We would recommend a paired data structure for future research evaluations, to control for race as a confounding variable but also to assess longitudinal changes in students who have further handson learning interventions.

Another limitation of this study is the fact it focused on novice students acquiring foundational knowledge of correct operator and patient positioning. Ergonomics is an applied science and clinicians will adjust their position as they work. Therefore, to have a full assessment of proper ergonomic compliance students should be evaluated during live patient procedures in the clinical setting, as demonstrated by previous studies. ${ }^{19,29,30}$ Due to the lack of randomized controlled trials regarding the effects of ergonomic interventions there is a strong need for further investigation. ${ }^{17}$ 
Since this was a convenience sample, the use of loupes among the novice DDS students could not be standardized. Many students had purchased their own loupes from a variety of vendors and had been consistently using them in the laboratory practice setting. We felt removing the loupes from students who were already acclimated to them would have too significant an impact on their posture. However, the frequency of loupes use was similar between groups: 13 case group participants $62 \%$ and 15 control group participants $75 \%$ wore loupes. 


\section{CONCLUSIONS}

Direct hands-on instruction positively affects proper ergonomic compliance. Students can benefit from inter-professional learning opportunities with fellow graduate physical therapy students. However, historical data on the study of ergonomics shows that without continued feedback students become less confident in their ability to maintain proper ergonomic positioning. ${ }^{24}$ Therefore continued feedback opportunities should remain part of the cumulative dental curriculum 
Table 1.1 Rubric for Ergonomic Compliance Evaluation

\begin{tabular}{|c|c|c|c|}
\hline Rubric & Ideal & Acceptable & Unacceptable \\
\hline Hip Flexion & $\begin{array}{l}\text { The height is adjusted so } \\
\text { hip flexion is greater than } \\
90 \text { degrees. }\end{array}$ & $\begin{array}{l}\text { The height is adjusted } \\
\text { slightly low so hip flexion } \\
\text { is } 90 \text { degrees. }\end{array}$ & $\begin{array}{l}\text { The height is adjusted so } \\
\text { hip flexion is less than } 90 \\
\text { degrees. The knees are } \\
\text { higher than the pelvis. }\end{array}$ \\
\hline Lumbar Positioning & $\begin{array}{l}\text { The lumbar has been } \\
\text { adjusted to fit into the } \\
\text { curve of the lumbar } \\
\text { lordosis (must make } \\
\text { contact with spine). }\end{array}$ & $\begin{array}{l}\text { The lumbar is positioned } \\
\text { slightly above or slightly } \\
\text { beneath the lumbar } \\
\text { lordosis (must make } \\
\text { contact with spine). }\end{array}$ & $\begin{array}{l}\text { The lumbar is positioned } \\
\text { so high it obstructs the } \\
\text { shoulders or so low it } \\
\text { rests on the gluteal area } \\
\text { (fails to make contact } \\
\text { with spine). }\end{array}$ \\
\hline Shoulder Abduction & $\begin{array}{l}\text { The shoulders are } \\
\text { abducted no more than } 20 \\
\text { degrees. }\end{array}$ & $\begin{array}{l}\text { The shoulders are } \\
\text { abducted between } 20 \text { and } \\
45 \text { degrees. }\end{array}$ & $\begin{array}{l}\text { The shoulders are } \\
\text { abducted beyond } 45 \\
\text { degrees. }\end{array}$ \\
\hline Neck Flexion & $\begin{array}{l}\text { The flexion of the neck is } \\
\text { no more than } 20 \text { degrees. }\end{array}$ & $\begin{array}{l}\text { The flexion of the neck is } \\
\text { between } 20 \text { and } 40 \\
\text { degrees. }\end{array}$ & $\begin{array}{l}\text { The flexion of the neck is } \\
\text { more than } 40 \text { degrees. }\end{array}$ \\
\hline $\begin{array}{l}\text { Thoracic Posture (in } \\
\text { relation to forward head } \\
\text { posture) }\end{array}$ & $\begin{array}{l}\text { The thoracic spine is in a } \\
\text { neutral position (vertical), } \\
\text { or the spine is pivoted at } \\
\text { the hip with no flexion of } \\
\text { the cervical or lumbar } \\
\text { regions. }\end{array}$ & $\begin{array}{l}\text { The spine is in a hunched } \\
\text { forward position } \\
\text { (increased thoracic } \\
\text { kyphosis), with up to one } \\
\text { inch of anterior head } \\
\text { carriage. }\end{array}$ & $\begin{array}{l}\text { The spine is in a hunched } \\
\text { forward position } \\
\text { (increased thoracic } \\
\text { kyphosis), with more than } \\
\text { one inch of anterior head } \\
\text { carriage }\end{array}$ \\
\hline $\begin{array}{l}\text { Lateral Flexion of the } \\
\text { Spinal Column }\end{array}$ & $\begin{array}{l}\text { No lateral flexion of the } \\
\text { spinal column present. }\end{array}$ & $\begin{array}{l}\text { The spine has slight } \\
\text { lateral flexion away from } \\
\text { or toward the dominant } \\
\text { hand, up to } 25 \text { degrees. }\end{array}$ & $\begin{array}{l}\text { The spine has lateral } \\
\text { flexion more than } 25 \\
\text { degrees, typically to the } \\
\text { side of the dominant } \\
\text { hand. }\end{array}$ \\
\hline $\begin{array}{l}\text { Elbow Flexion (patient } \\
\text { chair height) }\end{array}$ & $\begin{array}{l}\text { The height of the patient's } \\
\text { mouth is matched to the } \\
\text { height of the operator's } \\
\text { wrists when the elbow is } \\
\text { held at a neutral } 90 \text { degree } \\
\text { angle. }\end{array}$ & $\begin{array}{l}\text { The height of the patient's } \\
\text { mouth is slightly lower/ } \\
\text { higher than the height of } \\
\text { the clinician's wrists. } \\
\text { Creating up to } 25 \text { degrees } \\
\text { of inclining or declining } \\
\text { flexion in the elbow. ( } 90 \text { - } \\
115 \text { degrees of elbow } \\
\text { flexion) }\end{array}$ & $\begin{array}{l}\text { The height of the patient's } \\
\text { mouth is higher than the } \\
\text { height of the clinician's } \\
\text { wrists. Placing the arms } \\
\text { into inclining flexion } \\
\text { beyond } 25 \text { degrees from } \\
\text { the elbow. (>115 degrees } \\
\text { of elbow flexion) }\end{array}$ \\
\hline $\begin{array}{l}\text { Angle of the } \\
\text { Maxillary Arch: }\end{array}$ & $\begin{array}{l}\text { The patient is in a supine } \\
\text { position with the neck } \\
\text { tipped so the maxillary } \\
\text { arch is at a minimum } \\
\text { vertical (ideally beyond } \\
\text { the vertical) }\end{array}$ & \multirow[t]{2}{*}{$\begin{array}{l}\text { The arches are neutral, } \\
\text { with the occlusion plane } \\
\text { close to vertical. The } \\
\text { maxilla may be slightly } \\
\text { angled towards the } \\
\text { patient's chest. }\end{array}$} & \multirow[t]{2}{*}{$\begin{array}{l}\text { The clinician is working } \\
\text { on the mandibular arch } \\
\text { when positioned for the } \\
\text { maxillary or vice versa. }\end{array}$} \\
\hline Mandibular Arch & $\begin{array}{l}\text { The patient is in a supine } \\
\text { position with the chin } \\
\text { angled down toward the } \\
\text { chest. }\end{array}$ & & \\
\hline
\end{tabular}


Table 1.2 Picture Rubric Utilized for Evaluation

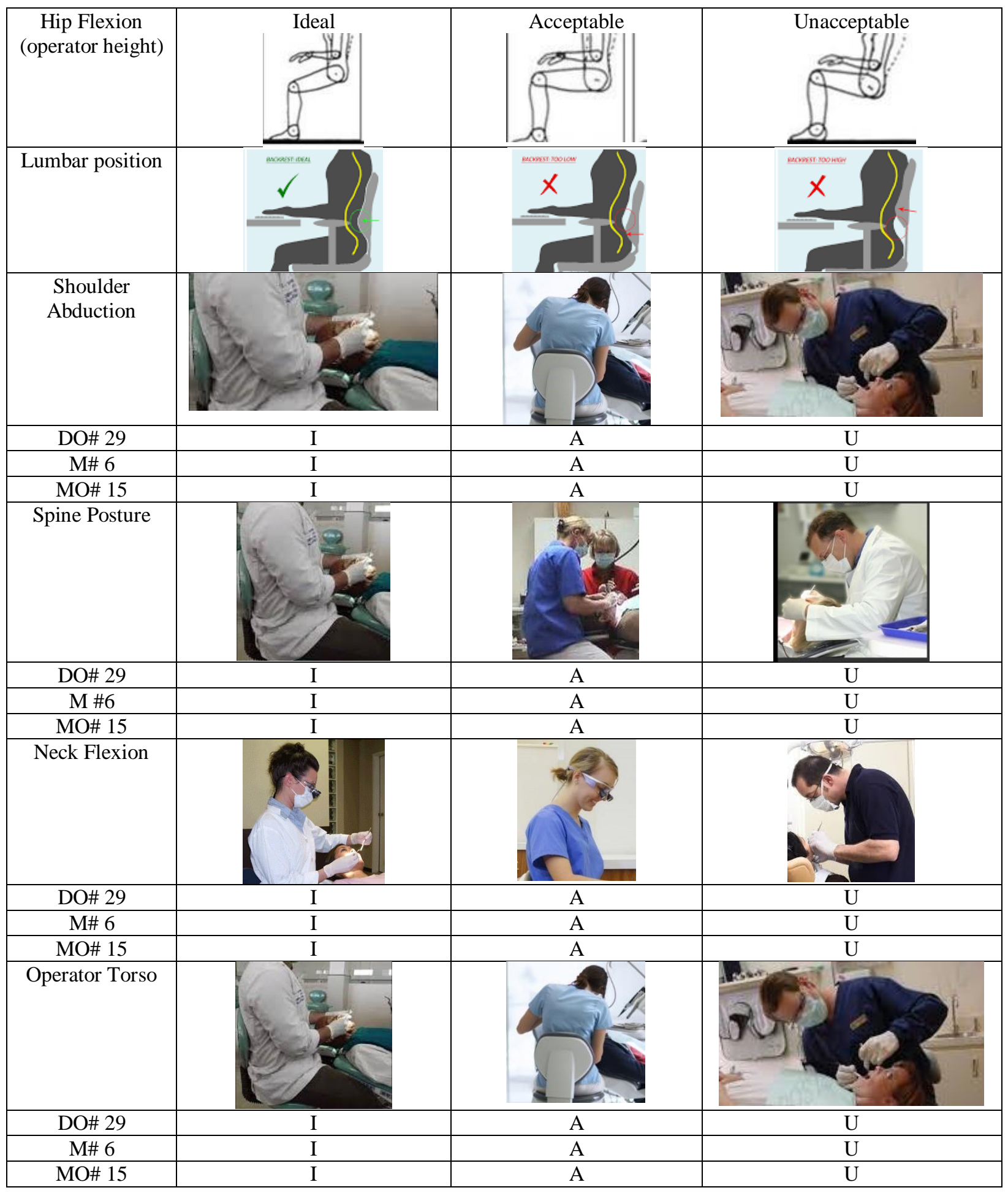




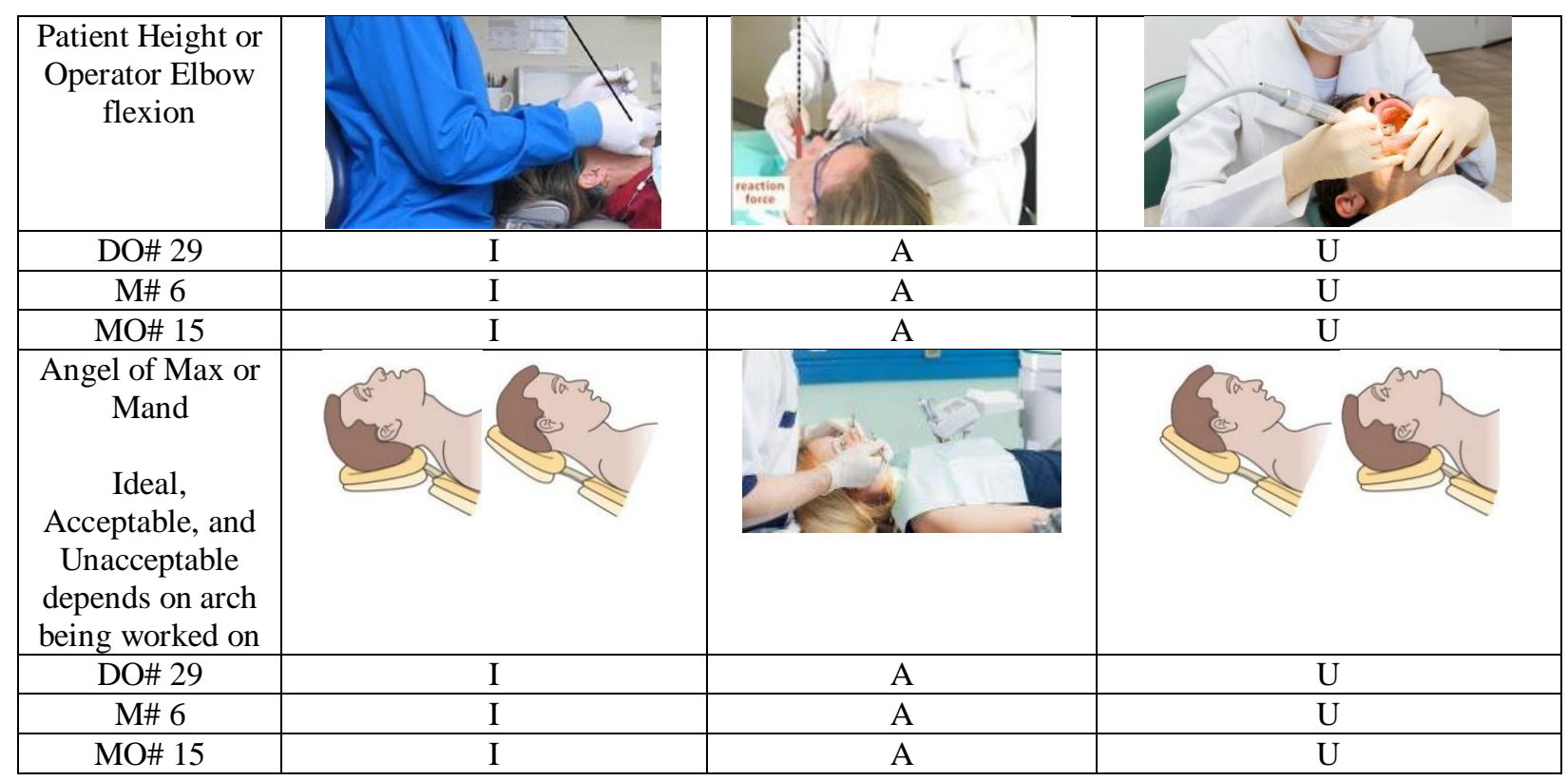


Table 2.1 Demographic Information Survey

Name:

Please respond to this brief demographic questionnaire with a check mark. You may decline to respond to any question.

1. Gender

Male $\square \quad$ Female $\square \quad$ Prefer not to respond $\square$

2. Age $\quad$ Prefer not to respond $\square$

Less than 20 years old $\square$

20-24 years old $\square$

25-29 years old $\square$

30-34 years old $\square$

35-39 years old $\square$

More than 40 years old $\square$

3. Race, which ethnicity do you most identify yourself as? $\quad$ Prefer not to respond $\square$

Caucasian (white) $\square$

Native American $\square$

Asian / Pacific Islander $\square$

African American (black) $\square$

Hispanic or Latino $\square$

Other $\square$

Specify 
Table 2.2 Demographics

\begin{tabular}{|c|c|c|c|c|c|}
\hline & $\begin{array}{c}\text { MH Row } \\
\text { P-value }\end{array}$ & $\begin{array}{c}\text { Case Group } \\
\mathrm{N}\end{array}$ & $\begin{array}{c}\text { Case Group } \\
\%\end{array}$ & $\begin{array}{c}\text { Control Group } \\
\text { N }\end{array}$ & $\begin{array}{c}\text { Control Group } \\
\%\end{array}$ \\
\hline $\begin{array}{l}\text { Gender } \\
\text { Male } \\
\text { Female }\end{array}$ & $\mathrm{P}=0.880$ & $\begin{array}{l}11 \\
10\end{array}$ & $\begin{array}{l}52 \% \\
48 \%\end{array}$ & $\begin{array}{l}10 \\
10\end{array}$ & $\begin{array}{l}50 \% \\
50 \%\end{array}$ \\
\hline $\begin{array}{l}\text { Race } \\
\text { White } \\
\text { Hispanic } \\
\text { Asian } \\
\text { Black } \\
\text { Other }\end{array}$ & $\mathrm{P}=0.047$ & $\begin{array}{c}16 \\
2 \\
2 \\
1 \\
0\end{array}$ & $\begin{array}{c}76 \% \\
10 \% \\
4 \% \\
10 \% \\
0 \%\end{array}$ & $\begin{array}{l}9 \\
2 \\
6 \\
2 \\
1\end{array}$ & $\begin{array}{c}45 \% \\
10 \% \\
30 \% \\
10 \% \\
5 \%\end{array}$ \\
\hline $\begin{array}{l}\text { Age Range } \\
20-24 \text { years } \\
25-29 \text { years } \\
\text { 30-34 years } \\
\text { 34-39 years }\end{array}$ & $\mathrm{P}=.748$ & $\begin{array}{c}13 \\
7 \\
1 \\
0\end{array}$ & $\begin{array}{c}62 \% \\
33 \% \\
5 \% \\
0 \%\end{array}$ & $\begin{array}{c}13 \\
5 \\
1 \\
1\end{array}$ & $\begin{array}{c}65 \% \\
25 \% \\
5 \% \\
5 \%\end{array}$ \\
\hline
\end{tabular}


Table 3.1 Mantel-Haenszel Row Mean Score for the Case and Control Groups

\begin{tabular}{|l|rrr|rrr|r|}
\hline \multirow{2}{*}{ Outcome Variable } & \multicolumn{3}{|c|}{ Case Group } & \multicolumn{3}{c|}{ Control Group } & \\
& Median & $\begin{array}{c}\text { Lower } \\
\text { Quartile }\end{array}$ & $\begin{array}{c}\text { Upper } \\
\text { Quartile }\end{array}$ & Median & $\begin{array}{c}\text { Lower } \\
\text { Quartile }\end{array}$ & $\begin{array}{c}\text { Upper } \\
\text { Quartile }\end{array}$ & P-value \\
\hline Hip Flexion & 2.00 & 2.00 & 2.00 & 2.00 & 2.00 & 2.00 & .949 \\
Lumbar Placement & 1.00 & 0 & 2.00 & 1.00 & 0 & 1.00 & .274 \\
Shoulder Abduction & 1.67 & 1.33 & 2.00 & 1.33 & 1.00 & 1.67 & .029 \\
Thoracic Posture & 2.00 & 1.67 & 2.00 & 1.67 & 1.33 & 2.00 & .201 \\
Neck Flexion & 1.67 & 1.00 & 2.00 & 1.00 & 1.00 & 1.67 & .266 \\
Lateral Spinal Flexion & 2.00 & 1.67 & 2.00 & 1.67 & 1.00 & 2.00 & .021 \\
Elbow Flexion & 1.33 & 1.00 & 1.67 & 1.00 & .50 & 1.33 & .066 \\
Arch Position & 1.33 & 1.33 & 1.33 & 1.00 & .67 & 1.33 & .067 \\
\hline
\end{tabular}

Table 3.2 Bivariate Unpaired T-test for Composite Scores

\begin{tabular}{|l|cccc|c|c|c|}
\hline Composite Score & N & Mean & St Dev & St Err & \multicolumn{2}{|c|}{ 95\% CI Mean } & P-value \\
\hline Case Group & 21 & 1.49 & .24 & .05 & 1.38 & 1.60 & .005 \\
Control Group & 20 & 1.22 & .22 & .05 & 1.18 & 1.38 & \\
\hline White & 25 & 1.48 & .23 & .05 & 1.38 & 1.57 & .005 \\
All Other Ethnicities & 16 & 1.26 & .23 & .06 & 1.13 & 1.38 & \\
\hline Female & 20 & 1.35 & .21 & .05 & 1.26 & 1.45 & .389 \\
Male & 21 & 1.42 & .29 & .06 & 1.29 & 1.55 & \\
\hline Aged 20-24 & 26 & 1.39 & .23 & .05 & 1.29 & 1.48 & .961 \\
25 and Older & 16 & 1.39 & .29 & .07 & 1.23 & 1.55 & \\
\hline
\end{tabular}


Table 4 Multivariate GLM Performed to the Bivariate Analysis

\begin{tabular}{|l|r|r|r|r|r|}
\hline Source & DF & Type III SS & Mean Square & F Value & Pr > F \\
\hline Group & 1 & 0.22123211 & 0.22123211 & 4.57 & 0.0395 \\
\hline Race Collapsed & 1 & 0.26363541 & 0.26363541 & 5.44 & 0.0254 \\
\hline Gender & 1 & 0.05316328 & 0.05316328 & 1.10 & 0.3019 \\
\hline Age Range Collapsed & 1 & 0.00380646 & 0.00380646 & 0.08 & 0.7809 \\
\hline
\end{tabular}


Table 5 Mean Scores of Ergonomic Compliance of the Case and Control Group

\begin{tabular}{|l|c|c|}
\hline \multicolumn{1}{|c|}{ Outcome Variable } & $\begin{array}{c}\text { Case Group } \\
\text { Mean Score }\end{array}$ & $\begin{array}{c}\text { Control Group } \\
\text { Mean Score }\end{array}$ \\
\hline Hip Flexion & 1.86 & 1.85 \\
Lumbar Placement & 0.95 & 0.7 \\
Shoulder Abduction & 1.59 & 1.3 \\
Thoracic Posture & 1.79 & 1.67 \\
Neck Flexion & 1.43 & 1.25 \\
Lateral Spinal Flexion & 1.76 & 1.43 \\
Elbow Flexion & 1.3 & 0.98 \\
Arch Position & 1.27 & 1.05 \\
Composite Score & 1.5 & 1.28 \\
\hline
\end{tabular}


Figure 1 Box Plot for Composite Scores of Ergonomic Compliance

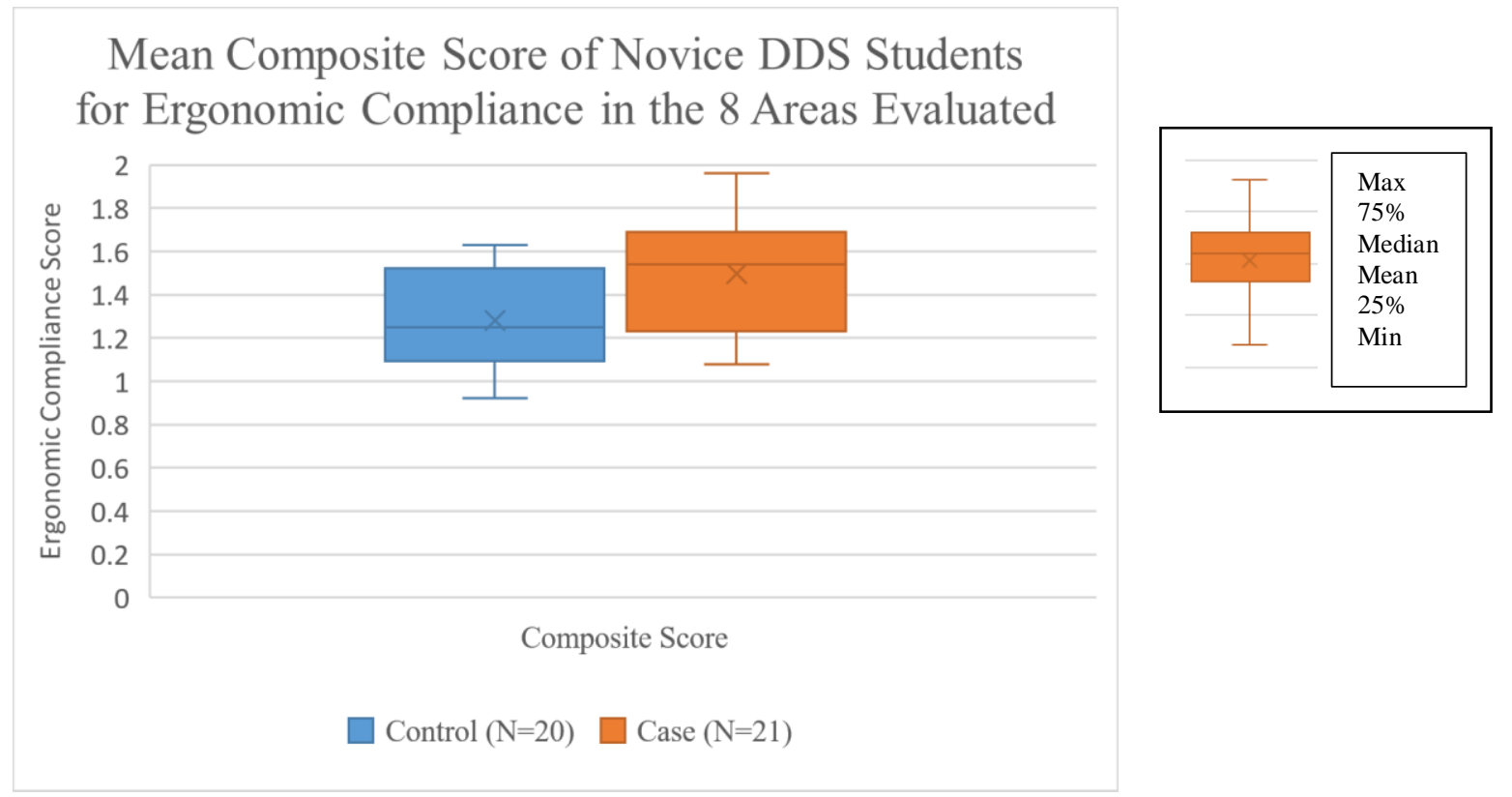




\section{REFERENCES}

1. Hayes MJ, Smith DR, Taylor JA. Musculoskeletal disorders in a 3 year longitudinal cohort of dental hygiene students. J. Dent. Hyg. 2014;88(1):36-41.

2. Hayes M, Cockrell D, Smith DR. A systematic review of musculoskeletal disorders among dental professionals. Int J Dent Hyg 2009;7(3):159-165.

3. Morse T, Bruneau H, Michalak-Turcotte $\mathrm{C}$, et al. Musculoskeletal disorders of the neck and shoulder in dental hygienists and dental hygiene students. J. Dent. Hyg. 2007;81(1):10.

4. Gambhir E, Singh G, Sharma S, Brar R, Kakar H. Occupational Health Hazards in Current Dental Profession- A Review.

5. Kwon Y, Kim J-W, Heo J-H, Jeon H-M, Choi E-B, Eom G-M. The effect of sitting posture on the loads at cervico-thoracic and lumbosacral joints. Technol. Health Care 2018;26(S1):409-418.

6. Valachi B, Valachi K. Mechanisms leading to musculoskeletal disorders in dentistry. The Journal of the American Dental Association 2003;134(10):1344-1350.

7. Samoladas E, Barmpagianni C, Papadopoulos DV, Gelalis ID. Lower back and neck pain among dentistry students: a cross-sectional study in dentistry students in Northern Greece. Eur. J. Orthop. Surg. Traumatol. 2018;28(7):1261-1267.

8. Lindfors $\mathrm{P}$, von Thiele $\mathrm{U}$, Lundberg $\mathrm{U}$. Work characteristics and upper extremity disorders in female dental health workers. J Occup Health 2006;48(3):192-197.

9. Humann P, Rowe DJ. Relationship of musculoskeletal disorder pain to patterns of clinical care in california dental hygienists. J. Dent. Hyg. 2015;89(5):305-312.

10. Gaowgzeh RA, Chevidikunnan MF, Al Saif A, El-Gendy S, Karrouf G, Al Senany S. Prevalence of and risk factors for low back pain among dentists. J Phys Ther Sci 2015;27(9):2803-2806.

11. Wijnhoven HAH, de Vet HCW, Picavet HSJ. Prevalence of musculoskeletal disorders is systematically higher in women than in men. Clin. J. Pain 2006; 22(8):717-724.

12. Valachi PT, MS, CEAS B, Valachi DDS K. Preventing musculoskeletal disorders in clinical dentistry. JADA 2003;134:1604-1612.

13. Peros K, Vodanovic M, Mestrovic S, Rosin-Grget K, Valic M. Physical fitness course in the dental curriculum and prevention of low back pain. J Dent Educ 2011;75(6):761-767.

14. Rivilis I, Van Eerd D, Cullen K, et al. Effectiveness of participatory ergonomic interventions on health outcomes: a systematic review. Appl Ergon 2008;39(3):342-358.

15. Baumann A, Holness DL, Norman P, Idriss-Wheeler D, Boucher P. The Ergonomic Program Implementation Continuum (EPIC): integration of health and safety--a process evaluation in the healthcare sector. J. Safety Res. 2012;43(3):205-213. 
16. Szeto GPY, Wong TKT, Law RKY, et al. The impact of a multifaceted ergonomic intervention program on promoting occupational health in community nurses. Appl Ergon 2013;44(3):414-422.

17. Mulimani P, Hoe VC, Hayes MJ, Idiculla JJ, Abas AB, Karanth L. Ergonomic interventions for preventing musculoskeletal disorders in dental care practitioners. Cochrane Database Syst. Rev. 2018;10:CD011261.

18. Garbin AJÍ, Garbin CAS, Diniz DG, Yarid SD. Dental students' knowledge of ergonomic postural requirements and their application during clinical care. Eur. J. Dent. Educ. 2011;15(1):31-35.

19. Partido BB. Dental Hygiene Students' Self-Assessment of Ergonomics Utilizing Photography. J Dent Educ 2017;81(10):1194-1202.

20. Garcia PPNS, Gottardello ACA, Wajngarten D, Presoto CD, Campos JADB. Ergonomics in dentistry: experiences of the practice by dental students. Eur. J. Dent. Educ. 2017;21(3):175-179.

21. Presoto CD, Wajngarten D, Domingos PAS, Campos JADB, Garcia PPNS. Dental students' perceptions of risk factors for musculoskeletal disorders: adapting the job factors questionnaire for dentistry. J Dent Educ 2018;82(1):47-53.

22. Hooftman WE, van der Beek AJ, Bongers PM, van Mechelen W. Is there a gender difference in the effect of work-related physical and psychosocial risk factors on musculoskeletal symptoms and related sickness absence? Scand. J. Work. Environ. Health 2009;35(2):85-95.

23. McClure SK, Adams JE, Dahm DL. Common musculoskeletal disorders in women. Mayo Clin. Proc. 2005;80(6):796-802.

24. Cervera-Espert J, Pascual-Moscardó A, Camps-Alemany I. Wrong postural hygiene and ergonomics in dental students of the University of Valencia (Spain) (part I). Eur. J. Dent. Educ. 2018;22(1):e48-e56.

25. Shankarapillai R, Nair MA, George R. The effect of yoga in stress reduction for dental students performing their first periodontal surgery: A randomized controlled study. Int. J. Yoga 2012;5(1):48-51.

26. Gura ST. Yoga for stress reduction and injury prevention at work. Work 2002;19(1):3-7.

27. Monson AL, Chismark AM, Cooper BR, renik-Matejcek, TM. Effects of Yoga on Musculoskeletal Pain. JDH 2017;91(2):15-22.

28. Pîrvu C, Pătraşcu I, Pîrvu D, Ionescu C. The dentist's operating posture - ergonomic aspects. J. Med. Life 2014;7(2):177-182.

29. Garcia PPNS, Wajngarten D, Campos JADB. Development of a method to assess compliance with ergonomic posture in dental students. JEHP 2018; 7(44). 
30. Maillet JP, Millar AM, Burke JM, Maillet MA, Maillet WA, Neish NR. Effect of magnification loupes on dental hygiene student posture. J Dent Educ 2008;72(1):33-44. 